\title{
Reduced Graphene Oxide-Doped Poly(N-alkyl-3,4- dihydrothieno[3,4-b][1,4]oxazine) with High Sensitivity of Indole-3-Acetic Acid
}

\author{
Kai Qu ${ }^{1, \S}$, Shouli Ming ${ }^{1, \S}$, Haiyan Jia $^{1}$, Bin Guo ${ }^{2}$, Ximei Liu ${ }^{3}$, Nannan Jian ${ }^{l}$, Guifang Niu ${ }^{3}$, \\ Baoyang $\mathrm{Lu}^{3, *}$ and Jingkun $\mathrm{Xu}{ }^{1,4^{*}}$ \\ ${ }^{1}$ School of Chemistry \& Chemical Engineering, Jiangxi Science \& Technology Normal University, \\ Nanchang 330013, China \\ ${ }^{2}$ College of Science, Nanjing Forestry University, Nanjing 210037 Jiangsu, China \\ ${ }^{3}$ School of Pharmacy, Jiangxi Science \& Technology Normal University, Nanchang 330013, China \\ ${ }^{4}$ School of Chemistry and Molecular Engineering, Qingdao University of Science and Technology, \\ Qingdao 266042, Shandong, China \\ *E-mail: 1by1258@163.com; xujingkun1971@yeah.net \\ $\S$ These authors contributed equally to this work.
}

doi: $10.20964 / 2018.12 .12$

Received: 11 August 2018 / Accepted: 6 September 2018 / Published: 5 November 2018

\begin{abstract}
A highly sensitive electrochemical sensor for detecting indole-3-acetic acid (IAA) was constructed based on the composite of poly(N-methyl-3,4-dihydrothieno[3,4-b][1,4]oxazine) (PMDTO) and reduced graphene oxide (RGO) (PMDTO/RGO). The PMDTO/RGO modified electrode was prepared by electrochemical polymerization of MDTO followed by the electrochemical reduction GO in their homogeneous aqueous solution. SEM demonstrated that PMDTO was covered with plate-like graphene through the two-step electrodeposition. The RGO, featuring large surface area and excellent conductivity, could not only improve the conductivity of the sensor, but also load more PMDTO to amplify the signal. The fabricated electrochemical sensor showed a low detection limit of $3 \times 10^{-8} \mathrm{M}$ and a wide linear range from 0.1 to $10 \mu \mathrm{M}$ for the recognition of IAA.
\end{abstract}

Keywords: poly(N-methyl-3,4-dihydrothieno[3,4-b][1,4]oxazine), sensor, indole-3-acetic acid, graphene oxide

\section{FULL TEXT}

(C) 2018 The Authors. Published by ESG (www.electrochemsci.org). This article is an open access article distributed under the terms and conditions of the Creative Commons Attribution license (http://creativecommons.org/licenses/by/4.0/). 